\title{
Estudio de Cohorte de Estudiantes de la UNED: una Aproximación al Análisis de Abandono
}

\author{
(A cohort study on UNED students: an approximation \\ to drop-out analyisis)
}

Javier Callejo

UNED (España)

\begin{abstract}
RESUMEN: El abandono es una de las principales amenazas con las que se encuentra la enseñanza a distancia, especialmente en su comparación con las universidades presenciales. No obstante, su análisis ha partido frecuentemente de los mismos procedimientos aplicados en este segundo tipo de enseñanza. Así, se suele considerar como abandono aquella situación en la que un alumno, que estaba matriculado durante un curso, deja de estarlo al siguiente. Es decir, la ruptura de la continuidad inmediata se considera abandono. Sin embargo, tal concepción temporal parece distanciarse del sistema del tiempo imperante en la enseñanza a distancia, proyectado más a largo plazo y siempre abierto a las irrupciones de las circunstancias vitales (familiares, laborales, etc.) de sus estudiantes. Por ello, en este trabajo se realiza una aproximación al abandono desde un estudio que aborda la evolución de los estudiantes desde el largo plazo.
\end{abstract}

Abandono - Análisis longitudinal - Cohortes de estudiantes - Enseñanza universitaria a distancia

SUMMARY: Drop-out is one of the main threats to distance education, particularly if compared with facetoface universities. However, drop-out analysis in distance education has often followed the same procedures as in faceto-face institutions. The most common drop-out definition establishes that students have abandoned the institution when they do not register for a subsequent school year; that is, the immediate rupture of the relationship with the institution is considered drop-out. However, such a approximation does not fit with the time patterns common in distance education, which involve longer term relationships and more openness to disruptures related to the students' needs (family, work, etc.). This paper examines the long term evolution of drop-out in distance education.

Drop-out - Longitudinal analysis - Students' cohorts - University distance education 


\section{INTRODUGGIÓN A OTRA GESTIÓN DEL TIEMPO}

Alrededor del $8 \%$ de las personas que se han matriculado en alguna de las carreras universitarias de la UNED, a lo largo de los dos últimos decenios, han obtenido la titulación que buscaban. Un porcentaje que significa cerca de cuarenta mil titulados. El tamaño de la proporción queda soslayado cuando se toca el volumen de personas que han salido al mercado de trabajo, más cualificado y profesional, desde esta universidad. En bruto, sin mayor contextualización, el porcentaje ofrecido puede llegar a generar cierto desasosiego. En especial, si se llega a identificar los que no han llegado con abandono. Pero, como suele ocurrir, los números, por sí solos, tienden más a ocultar, concentrando la mirada en un único punto, que a mostrar una realidad, que, en su complejidad, escapa siempre a la síntesis impuesta por un indicador, una tasa o un porcentaje. Además, entre otras objeciones metodológicas, ha de hacerse la de que buena parte de los que iniciaron sus estudios, se encuentran todavía matriculados en la UNED, ya sea porque tal matriculación ha sido reciente, ya porque, a pesar de ser muchos los años de esfuerzo, no cejan en ir lentamente en pos de su objetivo, la titulación. La gestión del tiempo en la enseñanza a distancia aparece como distinta a la que realiza el alumno de la enseñanza presencial: sus tiempos son más largos y, lo que tal vez sea más importante, aparece de manera borrosa tanto:

a) el inicio, pues los estudiantes se matriculan en una decisión impulsiva y, después, ese curso se queda sin que el alumno haga nada, para matricularse, por ejemplo, dos años después, ya siendo consciente de la realidad y el esfuerzo al que se enfrenta.

b) el final, que tiende a ser colocado a largo plazo, desde la asunción de que los estudios, especialmente si son de nivel universitario, han de compaginarse con otras actividades laborales o familiares.

c) el proceso, abierto a repetidas discontinuidades, en la medida que los propios estudios se encuentran subordinados a las presiones de otras funciones sociales de mayor requerimiento.

Por lo tanto, la realidad que ocupa aquí nuestro interés tiene, a su vez, dos fuentes de complejidad. Por un lado, la diferencial realidad de los alumnos de la enseñanza a distancia en nuestro país. Son alumnos que, en su mayor parte, compaginan sus estudios con otras obligaciones laborales y familiares. Su disponibilidad para el estudio es relativamente reducida y el esfuerzo vital exigido es mayor. Por lo tanto, la probabilidad de quedarse en el camino es alta. Lo que para un alumno «normal» (presencial) podría significar un leve contratiempo -un tema difícil dentro del programa, una asignatura complicada, un texto de difícil comprensión, un suspenso tras una notable inversión de tiempo, etc.- se convierten en problemas y germen para el desaliento, en el caso del alumno a distancia. Son muchos los que, al realizar su matrícula por primera vez en la enseñanza a 
distancia, se encuentran con que sus estimaciones de disponibilidad temporal eran exageradas, cuando no ilusorias, más alimentadas por el deseo y la voluntad, que por un análisis de su entorno inmediato y sus condicionantes. A ello hay que añadir, que esta universidad está abierta a todos los que han pasado la prueba de selectividad. No existen otros filtros ni procesos de selección previos.

La otra fuente que ha de servir de contexto de la proporción señalada se encuentra en la propia organización universitaria, puesto que el dato global encubre la notable diferencia entre unas titulaciones y otras. Es más, también puede encubrir diferencias entre distintos momentos en la evolución de una misma titulación. El acercamiento a tales diferencias constituye el objetivo principal de este trabajo. Se pregunta sobre las distintas posibilidades de obtener el título universitario según se curse una carrera u otra; sobre el cómo, en términos de duración, se obtiene y la influencia de haberse matriculado en la carrera en una época u otra de la institucionalización de la titulación. También, intentando ahondar en algunos de los rasgos disponibles de los alumnos, quiénes son los que más posibilidades tienen de llegar a la titulación, en cada una de las carreras.

Las páginas que siguen a continuación pretenden una aproximación a los alumnos universitarios de la UNED desde una particular perspectiva: la evolución que va desde el inicio de la carrera en esta universidad a la obtención del grado de licenciado o ingeniero. La tentación para convertir tal perspectiva en una dimensión de rendimiento es alta, ya sea de los alumnos, ya sea de la propia institución universitaria, es alta. En el ámbito de la enseñanza universitaria, los estudios de cohortes tienden a estar vinculados con el rendimiento de los alumnos, en clave de rendi mi ento académico ${ }^{2}$, o con el rendimiento de la institución, especialmente los dirigidos a estudiar cohortes de licenciados. Es decir, el seguimiento de una cohorte se convierte en instrumento para observar empíricamente un concepto como el rendimiento. Sin embargo, no es esa su pretensión.

Convertir los datos que aquí se presentan en un análisis del rendimiento significaría, en buena parte, asumir que la exclusiva función de las instituciones insertas en el nivel superior del sistema educativo es la de producir titulados. A la vez, que el conjunto del sistema educativo se centra en la regulación de títulos. Ha de reconocerse la importancia de tal ejercicio, pues, en buena medida, el sistema social delega en el sistema educativo la disposición de fuentes de heterogeneidad que permitan diferenciar, tras su preparación, a los considerados capaces para el ejercicio de una profesión o actividad. Visto así el conjunto del sistema educativo,

\footnotetext{
${ }^{1}$ Los datos que aquí se analizan han sido producidos por el Centro de Servicios Informáticos de la UNED y son los existentes a fecha del curso 1999-2000. Sin su inestimable ayuda, este trabajo no hubiera sido posible, por lo que al debido y sentido agradecimiento, ha de acompañarse el ruego de que sus profesionales sepan disculpar las continuas molestias a las que desde el IUED les sometemos, tanto para éste, como para otros trabajos.

${ }^{2}$ Un ejemplo se encuentra en el estudio de Justicia (1990).
} 
se corre el peligro de convertirlo en una especie de caja negra donde apenas se tenga en cuenta lo que pasa en su interior, sólo lo que de ella sale. En este caso, la cantidad y calidad de titulados. Los procesos de evaluación iniciados en el conjunto de la universidad española y particularmente en la UNED desmienten, en la práctica, tal reducción analítica, pudiéndose tomar como experiencias que ponen de relieve la importancia del propio paso por las instituciones universitarias de los alumnos. No se calibran sólo los resultados, el logro de la titulación, sino su transcurrir en las mismas.

Para convertirse en un análisis del rendimiento del alumnado y la institución, se exige una discusión, no exenta de fuertes e interesantes tensiones, sobre el significado de tal concepto. Su pretensión es menos ambiciosa: ofrecer al gunos datos, a modo de la consabida fotografía, sobre el paso de los alumnos por las distintas carreras universitarias de la UNED. Han de ser otros los que, a la luz de la validez que den a los resultados obtenidos, deriven consecuencias teóricas o metodológicas y, sobre todo, prácticas de gestión.

\section{EL ESTUDIO DE LAS GOHORTES}

El estudio de cohortes viene definido por el seguimiento de los alumnos que inician, en un determinado año, sus estudios universitarios en la UNED. Como hasta el momento, todos los estudios universitarios en esta institución constan de dos ciclos, tal inicio se establece con relación al comienzo del primer ciclo. Por lo tanto, forman parte de una misma cohorte los alumnos que inician por primera vez los estudios de una titulación en el primer ciclo de la UNED. Por lo tanto, se es consciente de que se deja de lado el creciente número de alumnos que acuden a esta institución universitaria con la experiencia, y los cursos y asignaturas aprobadas, de otras universidades, cuando el acceso lo hacen a través del segundo ciclo. Cuestión que ha de tenerse en cuenta a la hora de calibrar el peso del abandono, ya que este tipo de alumnos tiende a terminar sus estudios.

Los eventos o pasos que se han tenido en cuenta han sido la finalización del primer ciclo y la del segundo, constituyendo el logro de ésta la configuración de los observados como titulados. La finalización del primer ciclo conlleva haber aprobado todas las asignaturas de dicho ciclo y en el total de las titulaciones universitarias ofertadas por la UNED y observadas en este estudio ${ }^{3}$ comprende tres cursos. Sin embargo, en el caso del segundo ciclo, el número de cursos necesarios no es homogéneo, ya que la titulación de Ingeniería está compuesta por tres cursos en lugar de dos, como ocurre con el resto de titulaciones.

${ }^{3}$ Dada su reciente implantación, las titulaciones ofrecidas por la Escuela Superior de Ingenieros Técnicos I nformáticos han quedado fuera de la observación. 
Utilizando la metáfora del flujo, lo que se observa es: a) los que entran; b) los que alcanzan esa especie de lugar intermedio que es el primer ciclo; c) los que, dentro de los que empezaron al mismo tiempo, «salen» con la titulación buscada; d) los que continúan en el intento; y e) los que pidieron el traslado a otra universidad. Los que no se encuentran en ninguno de estos apartados, cabe incluirlos en el apartado del abandono, ya sea de los estudios universitarios en su conjunto, ya en el de la titulación iniciada en la UNED, trasladándose a otra universidad u otra carrera sin dejar constancia de ello, simplemente matriculándose en éstas.

Las variables consideradas han sido: a) años para la finalización, tomándose tramos de cinco en cinco años, excepto para el segundo tramo de la última cohorte, quedando realmente reducido a cuatro años; b) el género; y c) la edad. La opción por los tramos de cinco años deriva de que es la duración formal establecida para la casi totalidad de las carreras que se imparten en la UNED, con tres años para el primer ciclo y dos para el segundo. Sin embargo, tales tramos adquieren un significado distinto para Ingeniería, ya que su duración formal es de seis años.

Las tres cohortes que sirven de base al estudio tienen su origen en los cursos 1980, 1985 y 1990. En la elección de tales años de partida, se ha buscado un equilibrio entre el necesario distanciamiento de la actualidad para observar la evolución y que, a su vez, éste no fuese tan amplio que impidiese una interpretación en clave de esta misma actualidad, que es desde la que hay que actuar.

El total de alumnos constituyentes de las tres cohortes supera los treinta y cinco mil, como se muestra en la tabla I. Aproximadamente, el cuarenta por ciento son alumnos que han iniciado sus estudios de Derecho en alguno de los tres años. Sigue la carrera de empresariales, con al go más del dieciséis por ciento. Así, hasta llegar al 0,8\% que representan los alumnos matriculados por primera vez en los ciclos iniciales en Químicas de los tres años observados.

Tabla I: Total de alumnos de las 3 cohortes, según carrera

\begin{tabular}{lc} 
Titulación & total alumnos \\
DERECHO & 14245 \\
\hline ECONOMICAS & 2355 \\
\hline EDUCACION & 712 \\
\hline EMPRESARIAL & 5996 \\
\hline FILOLOGIA & 768 \\
\hline FILOSOFIA & 307 \\
\hline FISICAS & 828 \\
\hline GEOG-HISTORIA & 2731 \\
\hline INGENIEROS & 827 \\
\hline
\end{tabular}




\begin{tabular}{lr}
\hline MATEMATICAS & 592 \\
\hline POLITICAS & 975 \\
\hline PSICOLOGIA & 3483 \\
\hline QUIMICAS & 289 \\
\hline SOCIOLOGIA & 1258 \\
\hline & 35366 \\
\hline
\end{tabular}

El tamaño de cada una de las cohortes ha variado significativamente. No ha hecho más que reflejar el importante aumento en el número de alumnos matriculados que ha ido experimentado la UNED desde su nacimiento hasta el final del siglo XX. La tabla II refleja tal aumento de alumnos nuevos. En algunos casos, se ha multiplicado por más de diez, como ocurre con los casos de las titulaciones de Empresariales, Económicas, Físicas o Matemáticas. Ahora bien, adquieren el carácter de casos relevante el de las titulaciones de Ingeniería y Filología, pues multiplican por cuarenta y veinte el número de nuevos estudiantes que entran en las mismas en los diez años que transcurren desde la primera cohorte, 1980, a la última, 1990.

La tabla III muestra cómo se ha distribuido, entre las distintas titulaciones, el paso de los 3.507 alumnos nuevos registrados en 1980, a los 24.710 de 1990.

Tabla III: Alumnos por titulación y cohorte

\begin{tabular}{lrrr} 
& 1980 & 1985 & 1990 \\
DERECHO & 1949 & 4081 & 8215 \\
\hline ECONOMICAS & 152 & 311 & 1892 \\
\hline EDUCACION & 60 & 182 & 470 \\
\hline EMPRESARIAL & 439 & 855 & 4702 \\
\hline FILOLOGIA & 36 & 101 & 631 \\
\hline FILOSOFIA & & & 307 \\
\hline FISICAS & 48 & 95 & 685 \\
\hline GEOG-HISTORIA & 418 & 717 & 1596 \\
\hline INGENIEROS & 17 & 72 & 738 \\
\hline MATEMATICAS & 34 & 68 & 490 \\
\hline POLITICAS & & & 975 \\
\hline PSICOLOGIA & 328 & 595 & 2560 \\
\hline QUIMICAS & 26 & 72 & 191 \\
\hline SOCIOLOGIA & & & 1258 \\
\hline
\end{tabular}


Como puede verse en esta tabla III, en la última cohorte se incorporan dos titulaciones nuevas, Ciencias Políticas y Sociología, que inician su andadura en la UNED en el curso 1987-88; mientras que se recogen separadamente los alumnos de Filosofía y de Ciencias de la Educación, que caminan de manera unida hasta el curso 1993-94.

\subsection{COHORTE DE 1980}

De las tres cohortes observadas, la de 1980 es la de menor tamaño con 3.507 alumnos. Cuando se desciende a carreras como Ingenieros, el número de nuevos alumnos que la inician apenas llega a 17. Aún así, es de gran interés seguir la evolución de esta cohorte.

Acaban el primer ciclo de sus respectivas carreras 1.448 alumnos, lo que supone un notable $41,3 \%$ de los que habían empezado. Ahora bien, las diferencias entre las distintas carreras pueden considerarse relativamente notables: desde el $20,3 \%$ de los alumnos que empezaron empresariales, hasta los $58,3 \%$ de los alumnos de la, entonces, titulación de Filosofía y Ciencias de la Educación. No obstante, ha de reconocerse que tras tan alto porcentaje se encuentra el importante número de maestros que prácticamente convalidan el primer ciclo con el denominado curso de adaptación. Tras esta titulación, de difícil comparación con las demás, se encuentra la de Químicas, con un 46,2\% de alumnos nuevos en 1980 que terminan el primer ciclo, con unas características más comparables con el resto de titulaciones, incluida las de Empresariales e Ingenieros, que son las que menor proporción de éxitos en el primer ciclo presentan.

EI número de licenciados, como muestra la tabla IV, y era de esperar, se reduce. Hasta alcanzar los 910 . Es decir, el $62,8 \%$, del total de alumnos que iniciaron sus estudios en la UNED en 1980 y llegaron a pasar el primer ciclo, termina la carrera. La mayoría de los que han alcanzado el segundo ciclo, logran la titulación. El fin del primer ciclo aparece como el gran obstáculo. La otra interpretación es que, una vez pasado el primer ciclo, la motivación para obtener la titulación es mayor y, por lo tanto, la constante fuerza hacia el abandono de los estudios, que especialmente experimenta el alumnado con obligaciones laborales y familiares, es compensada.

Visto el conjunto de alumnos en los dos ciclos, del total de la carrera, la proporción que acaba con éxito es del 25,9\%. Por lo tanto, poco más de la cuarta parte de los alumnos que iniciaron la carrera consiguen terminarla. Una proporción nada desdeñable y que, además, encubre un esfuerzo continuo de muchos años en algunos casos. 
Tabla IV: Cohortes que inician estudios en 1980

\begin{tabular}{|c|c|c|c|c|c|}
\hline Titulaciones & $\underset{\text { Matriculados }}{\text { A }}$ & $\begin{array}{c}\text { B } \\
\text { Acaban } 1 \text { ciclo }\end{array}$ & $\begin{array}{c}\mathrm{C}=\mathrm{B} / \mathrm{Ax} 100 \\
\% \text { acaba } 1 \text { ciclo }\end{array}$ & $\begin{array}{c}\text { D } \\
\text { Titulados }\end{array}$ & $\begin{array}{c}E=D / A x 100 \\
\% \text { tit } / \text { mat }\end{array}$ \\
\hline DERECHO 80 & 1949 & 959 & 49,20 & 593 & 30,43 \\
\hline ECONOMICAS 80 & 152 & 67 & 44,08 & 55 & 36,18 \\
\hline EDUCACION 80 & 60 & *32 & 58,33 & 19 & 31,67 \\
\hline EMPRESARIAL 80 & 439 & 89 & 20,27 & 15 & 3,42 \\
\hline FILOLOGIA 80 & 36 & 14 & 38,89 & 9 & 25,00 \\
\hline FISICAS 80 & 48 & 13 & 27,08 & 9 & 18,75 \\
\hline GEOG-HIST 80 & 418 & 103 & 24,64 & 95 & 22,73 \\
\hline INGENIEROS 80 & 17 & 4 & 23,53 & 3 & 17,65 \\
\hline MATEMATICAS 80 & 34 & 11 & 32,35 & 3 & 8,82 \\
\hline PSICOLOGIA 80 & 328 & 144 & 43,90 & 98 & 29,88 \\
\hline QUIMICAS 80 & 26 & 12 & 46,15 & 11 & 42,31 \\
\hline
\end{tabular}

* Incluye quienes acaban primer ciclo y curso de adaptación

Por encima de la proporción media del $25,9 \%$, se encuentran titulaciones como: Químicas, Económicas, Filosofía y Ciencias de la Educación, Derecho y Psicología. Resulta curioso comprobar como se encuentran aquí titulaciones con un número relativamente bajo de alumnos, como Ciencias Químicas, y carreras con un número alto, como ocurre con el caso de Derecho o Psicología.

Alrededor de la proporción global de titulados, están Filología y Geografía e Historia. Algo más por debajo se encuentran Ciencias Físicas e Ingenieros. Con una tasa de titulados relativamente baja entre los alumnos que empezaron a estudiar en la UNED en 1980 se ofrecen las carreras de Matemáticas y E mpresariales.

Como puede observarse en la referida tabla IV, las diferencias entre las tasas de titulados entre las cohortes de unas carreras y otras pueden acercarse a los cuarenta puntos porcentuales. Diferencias que indican el escaso margen que hay para hablar de la UNED, al menos en este aspecto, como una realidad única. Es más, la mediación de las tradiciones académicas de las distintas disciplinas parecen tener un notable peso, salvo que se concluya que existen unas disciplinas y unas materias más adaptadas a la metodología de la enseñanza superior a distancia que otras.

Si la atención se lleva a la tabla V, donde se muestra la proporción de los que logran la titulación, entre los que ya pasaron con éxito el primer ciclo, se observa cómo las diferencias se fraguan principalmente en este segundo ciclo. Algo que 
parcialmente puede establecerse en la tabla IV comparando la diferencia máxima entre carreras, en puntos porcentuales, de los que finalizaron el primer ciclo, que no llega a los treinta, y tal diferencia entre los que finalizaron la carrera, que, como se ha dicho, se acerca a los cuarenta puntos. Pero sigamos ya por la tabla $\mathrm{V}$, pues mientras que más del $90 \%$ de los pasaron el primer ciclo en Ciencias Químicas y Geografía e Historia termina la carrera, tal porcentaje no llega al 20\% en Empresariales.

Tabla V: Porcentaje de titulados, entre los que acaban el primer ciclo

\begin{tabular}{lc} 
& \% tit/finl ciclo \\
\hline DERECHO 80 & 61,84 \\
\hline ECONOMICAS 80 & 82,09 \\
\hline EDUCACION 80 & 59,38 \\
\hline EMPRESARIAL 80 & 16,85 \\
\hline FILOLOGIA 80 & 64,29 \\
\hline FISICAS 80 & 69,23 \\
\hline GEOG-HIST 80 & 92,23 \\
\hline INGENIEROS 80 & 75,00 \\
\hline MATEMATICAS 80 & 27,27 \\
\hline PSICOLOGIA 80 & 68,06 \\
\hline QUIMICAS 80 & 91,67 \\
\hline
\end{tabular}

A la luz de estos datos y desde la perspectiva del alumno, puede decirse que mientras en algunas carreras, como Químicas o Geografía e Historia, pasar el primer ciclo supone «tener» buena parte del segundo conseguido; en otras titulaciones, como Empresariales o Matemáticas, todavía queda un trecho importante y obstáculos que parecen insalvables para una proporción importante de alumnos, para lograr el éxito definitivo, una vez conseguido superar el primer ciclo. Es más, las titulaciones que presentan menor porcentaje de titulados sobre el total e matriculados son las que muestran también menores porcentajes de alumnos que alcanzan la titulación, una vez pasado el primer ciclo.

La formalización de un traslado de expediente ha de tomarse únicamente como indicativo, en la comparación entre titulaciones, de: a) la capacidad de las carreras para retener a sus alumnos; b) el grado de vinculación con la UNED con que llegan los alumnos a las respectivas carreras. Un indicativo que ha de tomarse con relativas precauciones, ya que sólo recoge los traslados de quienes han solicitado formalmente tal traslado de expediente.

Según muestra la tabla VI, en Ciencias Físicas es donde se produce el mayor porcentaje de solicitudes de traslado de expediente, con un $16,7 \%$ de los alumnos que iniciaron la carrera. Le siguen Matemáticas, con un $8,8 \%$ tal vez derivado de las dificultades encontradas en la UNED para sacar adelante su carrera, y 
Derecho, con un porcentaje similar al anterior. Tanto las carreras de Filosofía y Ciencias de la Educación como Filología no presentan traslados de expediente. Vuelve a destacar el caso de Empresariales pues, a pesar del escaso porcentaje de alumnos que acaban la carrera en la UNED son pocos los que formalmente cambian a la misma carrera en otras universidades.

En el momento en que se recogen los datos referidos, han pasado veinte años desde que esta cohorte de alumnos empezó sus estudios en la UNED. Ello no parece ser obstáculo para que el $13,4 \%$ de los alumnos de Psicología y el $10,9 \%$ de los de Derecho se mantengan como estudiantes de tales titulaciones. Además, cabe pensar que el alumno que ha mantenido la vinculación durante tanto tiempo está fuertemente motivado para acabar la carrera y lleva buena parte del recorrido en la misma realizado, con lo que es previsible que se añadan al número de titulados de sus respectivas cohortes. En ambos casos, de lograr tales alumnos la titulación, el porcentaje de alumnos titulados sobre matriculados traspasaría el cuarenta por ciento. Es más, el 8,8\% de alumnos de Matemáticas que aún continúan abre la posi bilidad de duplicar el porcentaje total de titulados sobre matriculados iniciales. Sin embargo, en las carreras que presentan menor número de alumnos, como Ingeniería y Ciencias Químicas, no quedan alumnos de la cohorte de 1980 como estudiantes, por lo que la evolución de los porcentajes de titulados sobre matriculados se mantendrá como la reseñada en la tabla V.

Tabla VI: Porcentaje alumnos trasladan expediente y continúan en el curso 1999-2000, según carreras

\begin{tabular}{lrr} 
DERECHO 80 & Traslado Expt & Continúan \\
\hline ECONOMICAS 80 & 8,5 & 10,9 \\
\hline EDUCACION 80 & 5,3 & 5,3 \\
\hline EMPRESARIAL 80 & 0 & 6,7 \\
\hline FILOLOGÍA 80 & 1,0 & 2,1 \\
\hline FISICAS 80 & 0 & 5,6 \\
\hline GEOG-HIST 80 & 16,7 & 2,0 \\
\hline INGENIEROS 80 & 1,4 & 5,3 \\
\hline MATEMATICAS 80 & 6,0 & 0 \\
\hline PSICOLOGIA 80 & 8,8 & 8,8 \\
\hline QUIMICAS 80 & 4,6 & 13,4 \\
\hline
\end{tabular}

De forma tentativa, pueden obtenerse porcentajes de alumnos que abandonan cada una de las titulaciones. Se trataría de aquéllos que no han logrado su titulación; pero que tampoco se encuentran entre quienes han solicitado el traslado de expediente, que cabe interpretar como continuación de sus estudios en otra institución universitaria, ni entre los que aún continúan. Tal aproximación nos 
indica que la menor tasa de abandono de estudios se encuentra en las carreras de Químicas, Derecho, Psicología y E conómicas, con alrededor de la mitad de los alumnos que han abandonado los estudios en la UNED y, posiblemente, en otra universidad. Siguen Ciencias de la Educación y Ciencias Físicas, con porcentajes que superan el $60 \%$, para pasar, con Filología, Geografía e Historia, Ingenieros y Matemáticas, en las que presumiblemente ha abandonado entre dos tercios y tres cuartos de los alumnos que empezaron en 1980. Por último, Empresariales presenta un porcentaje de abandono que supera el $90 \%$, aun cuando puede encontrarse aquí un importante número de alumnos que han seguido sus estudios en otras instituciones universitarias, sin que conste la solicitud de su cambio en la matriculación.

El tiempo en el que se logra la titulación puede ser un indicativo importante de cara a la gestión, aun cuando todo señala que tal circunstancia ha de tomarse de una manera más holgada en esta universidad, dadas las características de un alumnado que tiende a establecer sus estrategias personales con relación a los estudios de distinta forma a como lo hace el alumnado presencial. Desde tal punto de vista, ha de señalarse, tabla VII, cómo el intervalo modal se encuentra habitualmente entre los 5 y los diez años, aun cuando de manera más cercana al límite superior del mismo.

En la comparación entre titulaciones, Ciencias Químicas y Económicas aparecen como las más «rápidas», en la medida en que presentan notables porcentajes de titulados en los cinco años de duración de la carrera. Los tramos temporales no se amoldan a Ingeniería, dado que son seis años la duración formal de sus estudios. Aún así, cabe destacar cómo todos sus titulados, cuyo número es cuatro, logran el éxito en el tramo que supera los diez años y no llega a los quince.

Las carreras en las que parece, a la vista del comportamiento de esta cohorte, más difícil conseguir el título en cinco años son, además de la ya señalada de Ingeniería, Filología, Matemáticas y Empresariales. Ahora bien, como se ha visto, la dificultad de lograr la titulación en esta carrera no sólo se encuentra en el tiempo. 
Tabla VII: Porcentaje de alumnos, sobre total de matriculados inicialmente en 1980, que se ha titulado, según años matriculados.

\begin{tabular}{lccccc} 
& $\%$ en 5 años & $\% 5-10$ años & $\begin{array}{c}\%+10 \text { años } \\
-15 \text { años }\end{array}$ & $\%+15$ años & $\begin{array}{c}\text { Porcentaje } \\
\text { total }\end{array}$ \\
\hline DERECHO 80 & 5,7 & 13,5 & 7,5 & 3,7 & 30,4 \\
\hline ECONOMICAS 80 & 10,6 & 15,7 & 7,3 & 2,7 & 36,3 \\
\hline EDUCACION 80 & 3,4 & 23,4 & 2,7 & 2,1 & 31,6 \\
\hline EMPRESARIAL 80 & 0,9 & 0,9 & 1,6 & 0 & 3,4 \\
\hline FILOLOGIA 80 & 0 & 5,6 & 19,4 & 0 & 25,0 \\
\hline FISICAS 80 & 2,1 & 4,2 & 6,3 & 6,3 & 18,9 \\
\hline GEOG-HIST 80 & 6,3 & 10,9 & 5,3 & 0,4 & 22,9 \\
\hline INGENIEROS 80 & 0 & 0 & 17,6 & 0 & 17,6 \\
\hline MATEMATICAS 80 & 0 & 5,8 & 3 & 0 & 8,8 \\
\hline PSICOLOGIA 80 & 1,5 & 6 & 13,7 & 8,4 & 29,6 \\
\hline QUIMICAS 80 & 19,1 & 15,3 & 7,9 & 0 & 42,3 \\
\hline
\end{tabular}

\subsection{COHORTE DE 1985}

El número de alumnos nuevos en las distintas carreras, observados en esta cohorte de 1985, se duplica con relación a la de cinco años antes, pasando a ser la de Ciencias Matemáticas la cohorte de menor tamaño, con 68 miembros. Lo que no cambia, como viene siendo habitual en la UNED desde su fundación, es el hecho de que Derecho ofrezca el número de alumnos mayor.

De los 7.149 alumnos que se matriculan por primera vez en el primer ciclo de una de las carreras de la UNED observadas, terminan el primer ciclo 2.442. Es decir, un $38,75 \%$, un porcentaje ligeramente inferior al que había deparado la cohorte de 1980. Ahora son Ingenieros y Filología las carreras que presentan menores porcentajes de alumnos que acaban el primer ciclo, con respecto al total de matriculados. Químicas y Físicas las que mayores porcentajes presentan. Es de destacar que se produce cierta homogeneización entre las carreras, entendiendo por ésta el menor rango de variabilidad entre los mayores y menores porcentajes de alumnos, según las titulaciones, que, iniciando la carrera al mismo tiempo en la UNED, acaban el primer ciclo.

Los porcentajes de los que superan el primer ciclo aumentan en Ciencias Físicas, considerablemente, Empresariales, Químicas, Geografía e Historia e Ingeniería, encontrándose aquí algunas de las que mostraron menores porcentajes en la cohorte de 1980. Sin embargo, disminuyen en Ciencias de la Educación, también considerablemente, Filología, Derecho y Económicas. Prácticamente 
se mantienen en niveles similares a lo experimentado con relación a la anterior cohorte observada en Matemáticas y Psicología.

EI porcentaje total de titulados, entre los que se matricularon, Ilega al 23,8\%. Ligeramente inferior al presentado en la cohorte de un lustro antes. Un descenso cuya explicación primera hay que buscarla en la disminución del porcentaje de titulados, en función del número de matriculados por primera vez en 1985, de carreras con tanto peso numérico como Derecho (descenso de más de cinco puntos porcentuales) o Económicas (más de once puntos). Ahora bien, aumenta considerablemente en carreras de menor peso numérico sobre el total de alumnos, como Ciencias de la Educación y Ciencias Físicas.

Tabla VIII: Cohortes que inician estudios en 1985

\begin{tabular}{|c|c|c|c|c|c|}
\hline Titulaciones & $\begin{array}{c}\text { A } \\
\text { Matriculados }\end{array}$ & $\begin{array}{c}\text { B } \\
\text { Acaban } 1 \text { ciclo }\end{array}$ & $\begin{array}{c}\mathrm{C}=\mathrm{B} / \mathrm{A} \times 100 \\
\% \text { acaba } 1 \text { ciclo }\end{array}$ & $\begin{array}{c}\text { D } \\
\text { Titulados }\end{array}$ & $\begin{array}{c}E=D / A x 100 \\
\% \mathrm{tit} / \mathrm{mat}\end{array}$ \\
\hline DERECHO 85 & 4081 & 1681 & 41,19 & 1015 & 24,87 \\
\hline ECONOMICAS 85 & 311 & 120 & 38,59 & 77 & 24,76 \\
\hline EDUCACION 85 & 182 & 97 & 41,21 & 85 & 46,7 \\
\hline EMPRESARIA 85 & 855 & 261 & 30,53 & 80 & 9,36 \\
\hline FILOLOGIA 85 & 101 & 30 & 29,7 & 22 & 21,78 \\
\hline FISICAS 85 & 95 & 41 & 43,16 & 30 & 31,58 \\
\hline GEOG-HIST 85 & 717 & 224 & 31,24 & 174 & 24,27 \\
\hline INGENIEROS 85 & 72 & 20 & 27,78 & 10 & 13,89 \\
\hline MATEMATICAS 85 & 68 & 21 & 30,88 & 8 & 11,76 \\
\hline PSICOLOGIA 85 & 595 & 239 & 40,17 & 173 & 29,08 \\
\hline QUIMICAS 85 & 72 & 38 & 52,78 & 31 & 43,06 \\
\hline
\end{tabular}

Como muestra la tabla VIII, Empresariales se mantiene como titulación con menos probabilidades de conseguir, entre los que la inician. En el polo opuesto, Ciencias de la Educación y Químicas, cuyos porcentajes se acercan a un panorama en la que casi la mitad de los que inician tales carreras consi guen terminarlas. Ahora bien, la relativa homogeneización que se había producido con respecto a los porcentajes de alumnos que superan el primer ciclo, apenas se encuentra presente con respecto a la finalización del segundo ciclo, pues las diferencias, en puntos porcentuales, entre las titulaciones con mayor y menor tasa de titulados por número de matriculados se mantienen con escasas variaciones con respecto a la cohorte de 1980. Por lo tanto, parece que en el segundo ciclo se renuevan las diferencias entre titulaciones.

Empresariales y Matemáticas, a pesar de que aumentan sus respectivos porcentajes, se mantienen como carreras con segundos ciclos más complicados para obtener la titulación, pues son las que menores porcentajes de titulados pre- 
sentan, entre los que acaban el primer ciclo. Dado que se encuentran en la misma Facultad, destaca el camino inverso experimentado por Económicas y Empresariales en este aspecto. Mientras Económicas «endurece» algo más el logro del segundo ciclo, comparándolo con los que han pasado el primero, Empresariales, a pesar de mostrarse como una de las carreras con un segundo ciclo con mayores dificultades, aumenta el cómputo de posibilidades de superar el segundo ciclo.

Tabla IX: Porcentaje de titulados, entre los que acaan el primer ciclo (cohorte 1985)

\begin{tabular}{lc} 
Titulaciones & \% tit/finl ciclo \\
DERECHO 85 & 60,38 \\
\hline ECONOMICAS 85 & 64,17 \\
\hline EDUCACION 85 & 87,63 \\
\hline EMPRESARIALES 85 & 30,65 \\
\hline FILOLOGIA 85 & 73,33 \\
\hline FISICAS 85 & 73,17 \\
\hline GEOG-HIST 85 & 77,68 \\
\hline INGENIEROS 85 & 50,00 \\
\hline MATEMATICAS 85 & 38,1 \\
\hline PSICOLOGIA 85 & 72,38 \\
\hline QUIMICAS 85 & 81,58
\end{tabular}

Los análisis anteriores han de tener en cuenta el total de alumnos que aún permanecen estudiando la misma carrera en la UNED. Una cifra que, como es previsible, ha de ser mayor en esta cohorte de 1985 que en la anterior de 1980, pues parece más «fácil» seguir estudiando después de quince años, que hacerlo después de veinte. De hecho, el porcentaje de alumnos que continúan aumenta en todas las carreras menos, curiosamente, en Psicología, evolución que puede explicarse parcialmente por el mantenimiento del porcentaje de titulados en esta disciplina, casi el 30\%, tanto en una cohorte como en otra, a pesar de que tienen cinco años de diferencia. No obstante, siguen siendo Derecho y Psicología las que ofrecen los mayores porcentajes de «corredores de fondo», de alumnos que siguen matriculándose, aun cuando han pasado quince años desde que lo hicieron por primera vez.

La distribución de los porcentajes de alumnos que formalmente han trasladado su expediente a otras universidades prácticamente se mantiene, si bien con la particularidad de un notable descenso en Ciencias Físicas y Químicas, hasta el punto que es Derecho la titulación que mayor porcentaje de traslados presenta. Por su lado, Ciencias de la Educación y Filología vuelven a mostrar la ausencia de solicitudes de traslado de expedientes. 
Estudio de Cohorte de Estudiantes de la UNED: una Aproximación al Análisis del Abandono

Tabla X: Porcentaje alumnos trasladan expediente y continúan en 1999-2000, según carreras (cohorte 85)

\begin{tabular}{lrc} 
Titulaciones & Traslado Expt & Continúan \\
DERECHO 85 & 9,4 & 14,1 \\
\hline ECONOMICAS 85 & 3,5 & 8,0 \\
\hline EDUCACION 85 & 0 & 11,0 \\
\hline EMPRESARIA 85 & 3,6 & 2,8 \\
\hline FILOLOGIA 85 & 0 & 10,9 \\
\hline FISICAS 85 & 8,4 & 12,6 \\
\hline GEOG-HIST 85 & 2,5 & 6,6 \\
\hline INGENIEROS 85 & 5,6 & 9,7 \\
\hline MATEMATICAS 85 & 8,8 & 10,3 \\
\hline PSICOLOGIA 85 & 3,7 & 12,8 \\
\hline QUIMICAS 85 & 2,8 & 11,1 \\
\hline
\end{tabular}

Prácticamente la mitad de los que consiguen la titulación en cada una de las carreras tardan más de cinco años y menos de diez. Un intervalo que, analizado linealmente, muestra que se acercan a su límite mínimo, los seis años, titulaciones como Ciencias de la Educación, Económicas, Físicas, Geografía e Historia y Químicas. A su límite superior, diez años, se aproxima especialmente Derecho. De esta manera y siguiendo la tabla XI, puede observarse que hay carreras en las que se logra mayor proporción de licenciados en menor tiempo, como es el caso de Filosofía y Ciencias de la Educación y Químicas. En el caso de esta última, más del noventa por ciento de sus licenciados logran la titulación antes de transcurrir diez años desde que se matricularon por primera vez. Sin embargo, las carreras que muestran menores proporciones de licenciados, como Empresariales, Matemáticas o Ingenieros no se encuentran entre las que más retardan tal logro, entre quienes lo han conseguido. Tal circunstancia puede interpretarse desde un mayor abandono o traslado no reflejado de estos estudiantes. 
Tabla XI: Distribución del porcentaje de licenciados según los años transcurridos desde el inicio de la matriculación, 1985, a la obtención de la titulación.

\begin{tabular}{lcccc}
\hline Titulaciones & $\%$ en 5 años & $\%$ 5-10 años & $\%+10$ años & Porcentaje total \\
\hline DERECHO 85 & 2,9 & 13,8 & 8,2 & 24,9 \\
\hline ECONOMICAS 85 & 7,8 & 13,2 & 3,8 & 24,8 \\
\hline EDUCACION 85 & 13,1 & 25,2 & 8,4 & 46,7 \\
\hline EMPRESARIA 85 & 2,7 & 4,7 & 2 & 9,4 \\
\hline FILOLOGIA 85 & 0 & 18,9 & 2,9 & 21,8 \\
\hline FISICAS 85 & 8,5 & 16,8 & 6,3 & 31,6 \\
\hline GEOG-HIST 85 & 8,9 & 12,1 & 3,3 & 24,3 \\
\hline INGENIEROS 85 & 2,8 & 9,8 & 1,3 & 13,9 \\
\hline MATEMATICAS 85 & 1,5 & 8,7 & 1,6 & 11,8 \\
\hline PSICOLOGIA 85 & 5,8 & 18,2 & 5,1 & 29,1 \\
\hline QUIMICAS 85 & 19,6 & 22,3 & 1,2 & 43,1 \\
\hline
\end{tabular}

\subsection{COHORTE DE 1990}

La cohorte de 1990 es la más numerosa entre las observadas, dejando constancia del notable incremento del alumnado en la UNED. Entre las carreras observadas, el número de alumnos es de 24.707. Hay que resaltar que el número de carreras analizadas pasa de once a catorce gracias a la introducción de las carreras de: Ciencias Políticas, Sociología y Filosofía, ya que lo que anteriormente se recogía como Filosofía y Ciencias de la E ducación (E ducación en la mayor parte de las tablas aquí reflejadas) pasa a formar dos titulaciones (y Facultades) separadas.

Hasta el momento, en esta cohorte se ha titulado el 8,5\% de los que empezaron en 1990. Es decir, un total de 2.110 alumnos. Han sobrepasado el primer ciclo 3.892, lo que supone algo más del $15,7 \%$ de los que empezaron. La distribución por carreras se muestra en la tabla XII; pero ya los datos ofrecidos muestran un notable descenso en las proporciones de titulados y de quienes acaban el primer ciclo. De hecho, el porcentaje total de titulados desciende a casi la tercera parte con respecto al presentado en la cohorte de 1985, algo que parcialmente puede explicarse por la relativa mayor «juventud» de la cohorte de 1990, de manera que sus componentes han tenido menos tiempo para acabar la carrera. Claro está, tal explicación tiene menos peso a la hora de enfrentarse al descenso en la proporción de quienes han superado el primer ciclo, de más de 23 puntos porcentuales.

Desde el descenso en las proporciones de quienes superan el primer ciclo, la variación entre unas carreras y otras en este aspecto es menor, pues apenas superan los 16 puntos porcentuales la diferencia entre la que presenta el mayor 
porcentaje de alumnos que han superado el primer ciclo, Derecho, y la que presenta el menor, Matemáticas. Hay que constatar que se encuentran por encima de la proporción global de quienes superan el primer ciclo carreras como: Derecho, Químicas y Ciencias de la Educación. El resto de carreras, lo que supone el 64\% de los alumnos matriculados, presentan porcentajes de alumnos que han superado el primer ciclo por debajo de la media global. Por lo tanto, no sólo la proporción global de quienes superan el primer ciclo baja notablemente con respecto a las cohortes anteriormente observadas sino que, salvo la excepción de Derecho, tal descenso es importante en buena parte de ellas. Así, la diferencia sobrepasa los treinta puntos porcentuales en los casos de Psicología, Químicas y Físicas.

Tabla XII: Cohortes que inician estudios en 1990

\begin{tabular}{lccccc} 
& A & B & C=B/Ax100 & D & E=D/Ax100 \\
\cline { 2 - 6 } Titulaciones & Matriculados & Acaban 1 cido & \% acaba 1 ciclo & Titulados & $\%$ tit/mat \\
\hline DERECHO 90 & 8215 & 1846 & 22,47 & 1075 & 13,09 \\
\hline ECONOMICAS 90 & 1892 & 173 & 9,14 & 82 & 4,33 \\
\hline EDUCACION 90 & 470 & 90 & 17,45 & 67 & 14,26 \\
\hline EMPRESARIAL 90 & 4702 & 725 & 15,42 & 226 & 4,81 \\
\hline FILOLOGIA 90 & 631 & 51 & 8,08 & 38 & 6,02 \\
\hline FILOSOFIA 90 & 307 & 33 & 10,75 & 23 & 7,49 \\
\hline FISICAS 90 & 685 & 83 & 12,12 & 38 & 5,55 \\
\hline GEOG-HIST 90 & 1596 & 194 & 12,16 & 107 & 6,7 \\
\hline INGENIEROS 90 & 738 & 52 & 7,05 & 26 & 3,52 \\
\hline MATEMATICAS 90 & 490 & 29 & 5,92 & 12 & 2,45 \\
\hline POLITICAS 90 & 975 & 74 & 7,59 & 57 & 5,85 \\
\hline PSICOLOGIA 90 & 2560 & 377 & 14,73 & 244 & 9,53 \\
\hline QUIMICAS 90 & 191 & 35 & 18,32 & 20 & 10,47 \\
\hline SOCIOLOGIA 90 & 1258 & 130 & 10,33 & 95 & 7,55 \\
\hline
\end{tabular}

EI fenómeno experimentado con respecto al primer ciclo, no hace sino proyectarse con respecto a las proporciones de titulados, con un descenso de las mismas. Así, mientras en la cohorte de 1985 las proporciones de titulados en Ciencias de la Educación, Químicas y Físicas eran del 46\%, 43\% y 31\%, pasan a ser respectivamente del $14 \%, 10 \%$ y $5 \%$, debiéndose tener en cuenta que la primera contenía tanto Filosofía como Educación. Ahora bien, ha de advertirse nuevamente que el tiempo disponible para acabar la carrera ha sido mayor, en cinco años, para la cohorte de 1985.

Cuando se analiza la proporción de alumnos que, habiendo superado el primer ciclo, alcanzan la titulación, con evoluciones distintas en función de las 
carreras. En Económicas, el porcentaje desciende en 17 puntos; 27 puntos en Físicas; 22 en Geografía e Historia; 24 en Químicas. Es decir, con la constante salvedad de que cabe esperar que un número importante de alumnos de estas carreras que ha pasado el primer ciclo las acaben en un período de tiempo más o menos breve, es como si algunas carreras tuvieran para esta cohorte de 1990 más dificultades. Sin embargo, la mayor parte de las otras carreras presenta proporciones de titulados, entre los que han pasado el primer ciclo, semejantes a las ofrecidas en las cohortes anteriormente observadas.

\begin{tabular}{|c|c|}
\hline Titulaciones & $\%$ tit/fin l ciclo \\
\hline DERECHO 90 & 58,23 \\
\hline ECONOMICAS 90 & 47,40 \\
\hline EDUCACION 90 & 74,44 \\
\hline EMPRESARIAL 90 & 31,17 \\
\hline FILOLOGIA 90 & 74,51 \\
\hline FILOSOFIA 90 & 69,70 \\
\hline FISICAS 90 & 45,78 \\
\hline GEOG-HIST 90 & 55,15 \\
\hline INGENIEROS 90 & 50,00 \\
\hline MATEMATICAS 90 & 41,38 \\
\hline POLITICAS 90 & 77,03 \\
\hline PSICOLOGIA 90 & 64,72 \\
\hline QUIMICAS 90 & 57,14 \\
\hline SOCIOLOGIA 90 & 73,08 \\
\hline
\end{tabular}

La sospecha de un menor número de titulados, en función del número de matriculados, parece tender a confirmarse cuando se comparan las distribuciones de los porcentajes de titulados entre los intervalos de años reales de duración de la misma. La tabla XIV ofrece tal distribución, aun cuando, en comparación con las anteriores, quede restringida a dos únicos intervalos, el de los alumnos que logran la titulación en cinco años, tiempo formal adscrito a las carreras observadas con la excepción de Ingeniería, y el de quienes lo han hecho a partir de 6 o más años.

La proporción de titulados en cinco años es notablemente baja en el caso de Matemáticas y Económicas. Relativamente alta en los de Educación y Filosofía. 
Estudio de Cohorte de Estudiantes de la UNED: una Aproximación al Análisis del Abandono

Tabla XIV: Distribución del porcentaje de licenciados según los años transcurridos desde el inicio de la matriculación, 1985, a la obtención de la titulación.

\begin{tabular}{llcc} 
Titulaciones & $\%$ en 5 años & $\%+5$ años & Porcentaje total \\
DERECHO 90 & 3,2 & 9,8 & 13 \\
\hline ECONOMICAS 90 & 1,3 & 2,9 & 4,2 \\
\hline EDUCACION 90 & 8,2 & 6 & 14,2 \\
\hline EMPRESARIAL 90 & 2 & 2,8 & 4,8 \\
\hline FILOLOGIA 90 & 3,6 & 2,5 & 6,1 \\
\hline FILOSOFIA 90 & 6,6 & 0,9 & 7,5 \\
\hline FISICAS 90 & 1,7 & 3,8 & 5,5 \\
\hline GEOG-HIST 90 & 2,7 & 4 & 6,7 \\
\hline INGENIEROS 90 & 1,8 & 1,7 & 3,5 \\
\hline MATEMATICAS 90 & 1,2 & 1,2 & 2,4 \\
\hline POLITICAS 90 & 2,1 & 3,7 & 5,8 \\
\hline PSICOLOGIA 90 & 3,7 & 5,9 & 9,6 \\
\hline QUIMICAS 90 & 5,1 & 5,2 & 10,3 \\
\hline SOCIOLOGIA 90 & 2,7 & 4,9 & 7,6 \\
\hline
\end{tabular}

Las diferencias entre la proporción de quienes obtienen la titulación en cinco años de las distintas cohortes aumentan notablemente con la de 1990. La variación más acusada, hacia un notable descenso, la encontramos en la carrera de Químicas: la proporción de licenciados en cinco años desciende en más de 15 puntos al comparar la cohorte de 1990 con las de 1980 y 1985. En Económicas, la evolución adquiere el mismo sentido, aun cuando con menor intensidad y todavía menor en Geografía e Historia y Físicas. En cualquier caso, aparecen como carreras en las que parece que se ha hecho más difícil obtener la titulación en los cinco años que marca la oferta de la UNED. Una evolución inversa ha experimentado Filología, aumentando la proporción de los que llegan en cinco años con respecto a las cohortes anteriores. Por otro lado, con escasas variaciones se encuentran Empresariales, Derecho e Ingeniería. Es decir, titulaciones con importante número de alumnos, como Derecho y Empresariales apenas han experimentando grandes fluctuaciones; pero son más las titulaciones en las que parece que los alumnos tienen más dificultades para la obtención del título en cinco años, que en las que parece que tienen menos. 
Tabla XV: Porcentaje alumnos trasladan expediente y continúan en curso 1999-2000, según carreras (cohorte 90)

\begin{tabular}{llc} 
Titulaciones & \% trasladan expdie. & \% Continúan \\
DERECHO 90 & 8,7 & 16,1 \\
\hline ECONOMICAS 90 & 3,7 & 3,3 \\
\hline EDUCACION 90 & 0 & 7,9 \\
\hline EMPRESARIAL 90 & 2,8 & 3,7 \\
\hline FILOLOGIA 90 & 0 & 2,7 \\
\hline FILOSOFIA 90 & 3,6 & 5,2 \\
\hline FISICAS 90 & 3,8 & 6,1 \\
\hline GEOG-HIST 90 & 1,9 & 10,5 \\
\hline INGENIEROS 90 & 3,1 & 7,3 \\
\hline MATEMATICAS 90 & 6,5 & 4,3 \\
\hline POLITICAS 90 & 0,9 & 5,9 \\
\hline PSICOLOGIA 90 & 2 & 9,4 \\
\hline QUIMICAS 90 & 5,8 & 7,3 \\
\hline SOCIOLOGIA 90 & 0,5 & 7,5 \\
\hline
\end{tabular}

Como muestra la tabla XV y, por otro lado, cabría esperar, los porcentajes de alumnos que continúan estudiando sus respectivas carreras aumentan en casi todas las titulaciones de la cohorte, con las notables excepciones de las de Psicología y Filología, además de, muy ligeramente, Económicas. Con respecto a la primera, tal vez lo extraño era el comportamiento de la cohorte de 1985, pues un $13,4 \%$ de los mismos continuaba cuando había empezado la carrera hacía más de quince años.

\section{APROXIMAGIONES AL ABANDONO}

Los datos que se han presentado anteriormente permiten una aproximación al abandono en la UNED. Al menos, a una concepción del abandono, pues, como se recoge en una obra anterior, los tipos y factores de abandono de los alumnos que pueden observarse son varios y distintos (García Aretio 2001). Algo que también está relacionado con lo que se entiende por alumno, pues aquí cabe diferenciar entre el alumno real, que hace un esfuerzo por sacar adelante los estudios elegidos, y el denominado «alumno ficticio», como aquel que se matricula en la UNED, atraído por la expectativa de obtener un título; pero que, a la hora de enfrentarse con los estudios, se encuentra con una realidad donde la motivación o, más frecuentemente disponibilidad de tiempo son escasas, de manera que no llega a ni a presentarse a una sola asignatura en condiciones 0 , a lo sumo, lo hace para recoger información de las características de las pruebas presenciales, 
Estudio de Cohorte de Estudiantes de la UNED: una Aproximación al Análisis del Abandono

por si decide retomar los estudios en un futuro y como ejercicio de un derecho adquirido por la propia matriculación.

Aquí, como se ha venido haciendo en el trabajo, se va a considerar como alumno a todos los que se han matriculado, se hayan presentado o no a algún examen. El concepto de abandono viene dado por aquellos alumnos que no han acabado la carrera, no continúan sus estudios en ella y no han solicitado traslado a otra universidad y lo que ello significaría de seguir los estudios en otra institución. En esta resta, habría que añadir aquellos alumnos que no continúan en el momento en que se recogen los datos (abril de 2000); pero que tienen previsto retomar los estudios tras un más o menos breve interrupción. $\mathrm{Ha}$ de tenerse en cuenta que esta circunstancia es más habitual de lo que podría parecer, ya que los alumnos, en buena parte con obligaciones familiares y laborales, van ajustando sus trayectorias curriculares a las circunstancias vitales. Así, según los datos de la encuesta realizada a los alumnos que se matriculan en el curso 2000-2001, el 29,3\% de los matriculados anteriormente han interrumpido al guna vez sus estudios en esa misma carrera en Ia UNED. Claro está, tal porcentaje aumenta entre los que se matricularon por primera vez en alguno de los años observados en nuestras cohortes. Así, asciende al $91,2 \%$ de los que iniciaron en 1980, al 75\% de los que lo hicieron en 1985 y al 61,6\% de quienes empezaron en 1990. Esto no sólo explica que la larga duración de los estudios se deba a las diversas interrupciones llevadas a cabo sino que también posibilita una estimación, aun cuando no sea excesivamente fina, de los alumnos que podrían continuar en el futuro, dentro de las respectivas cohortes de las carreras, y no lo hacen.

En la siguiente tabla, se muestran los porcentajes de alumnos en cada cohorte que, según la encuesta a los matriculados en el curso 2000/01, han interrumpido sus estudios, al menos alguna vez, en cada una de las carreras: 
Porcentaje de alumnos matriculados en el curso 2000/01 en cada una de las titulaciones y cohorte, que han interrumpido al menos alguna vez sus estudios, no matriculándose

\begin{tabular}{|lccc|}
\hline & NNICIO EN 1980 & INICIO EN 1985 & INICIO EN 1990 \\
\hline DERECHO & 98,2 & 72,2 & 57,6 \\
\hline ECONOMICAS & 50 & 50 & 38,5 \\
\hline EDUCACION & 100 & 100 & 71,4 \\
\hline EMPRESARIALES & 100 & 75 & 66,7 \\
\hline FILOLOGIA & 100 & - & 75 \\
\hline FILOSOFIA & - & 50 & - \\
\hline FISICAS & 66,7 & 66,7 & 66,7 \\
\hline GEOG-HIST & 100 & 60 & 68,4 \\
\hline INGENIEROS & & & 80 \\
\hline MATEMATICAS & & 100 & 75 \\
\hline POLITICAS & & & 45,5 \\
\hline PSICOLOGIA & 100 & 77,8 & 60 \\
\hline QUIMICAS & & & 25 \\
\hline SOCIOLOGIA & & & 85,5 \\
\hline
\end{tabular}

Estos porcentajes pueden servir de estimadores de los alumnos que podrían continuar y no han sido recogidos en la información de registros aquí utilizada. Para ello, se multiplican por los que continúan dentro de cada carrera. Las estimaciones resultantes son las siguientes.

Porcentajes de alumnos estimados que pueden continuar, no pudiéndose considerar como abandonos, en cada una de las carreras y cohortes

\begin{tabular}{lrrr} 
& 1980 & 1985 & 1990 \\
DERECHO & 10,70 & 10,18 & 9,27 \\
\hline ECONOMICAS & 2,65 & 4,00 & 1,27 \\
\hline EDUCACION & 6,70 & 11,00 & 5,64 \\
\hline EMPRESAR & 2,10 & 2,10 & 2,47 \\
\hline FILOLOGIA & 5,60 & - & 2,03 \\
\hline FISICAS & 1,33 & 8,40 & 4,07 \\
\hline GEOG-HIS & 5,30 & 3,96 & 7,18 \\
\hline INGENIERIA & 0 & - & 5,84 \\
\hline MATEMATICAS & - & 10,30 & 3,22 \\
\hline PSICOLOGIA & 13,40 & 9,96 & 5,64 \\
\hline QUIMICAS & 0 & - & 1,83 \\
\hline
\end{tabular}


Estudio de Cohorte de Estudiantes de la UNED: una Aproximación al Análisis del Abandono

\begin{tabular}{llll}
\hline FILOSOFIA & - & - & - \\
\hline POLITICAS & - & - & 3,41 \\
\hline SOCIOLOGIA & - & - & 5,04
\end{tabular}

Los cálculos que se llevan a cabo para evaluar el abandono en cada una de las titulaciones y cohortes se realizan a partir de la diferencia entre el total de matriculados en la cohorte de la titulación menos quienes han conseguido la titulación, han trasladado su expediente, continúan sus estudios y una mínima estimación, pues se toma como referencia un solo año, de los que podrían continuar sus estudios. El resultado es el siguiente:

Porcentajes de alumnos que abandonan, por cohorte y titulación

\begin{tabular}{lccc} 
& 1980 & 1985 & 1990 \\
DERECHO & 39,5 & 41,5 & 52,8 \\
\hline ECONOMICAS & 50,6 & 59,7 & 87,4 \\
\hline EDUCACION & 54,9 & 31,3 & 72,2 \\
\hline EMPRESAR & 91,4 & 82,1 & 86,2 \\
\hline FILOLOGIA & 63,8 & 67,3 & 89,3 \\
\hline FISICAS & 61,2 & 39,0 & 80,5 \\
\hline GEOG-HIS & 65,3 & 62,7 & 73,7 \\
\hline INGENIERIA & 76,4 & 70,8 & 80,2 \\
\hline MATEMATICAS & 73,6 & 58,8 & 83,5 \\
\hline PSICOLOGIA & 38,7 & 44,5 & 73,4 \\
\hline QUIMICAS & 50,0 & 43,0 & 74,6 \\
\hline FILOSOFIA & - & - & 83,7 \\
\hline POLITICAS & - & - & 84,0 \\
\hline SOCIOLOGIA & - & - & 79,4 \\
\hline
\end{tabular}

Realizando las ponderaciones correspondientes, en función del número de alumnos matriculados en cada carrera, en cada una de las carreras, se obtiene que, para el conjunto de la UNED observado, abandona el 50,8\% de los alumnos matriculados por primera vez en 1980; el 50\% entre los que lo hacen en 1985 y el $71,9 \%$ entre los de 1990, bien teniendo en cuenta que cabe suponer que la probabilidad de que regresen a sus estudios en la UNED algunos de los que ahora se dan como alumnos que han abandonado es mayor en esta última cohorte, superando los restrictivos estimadores utilizados.

Teniendo en cuenta la anterior advertencia, parece derivarse que la cohorte condiciona en mayor medida que la titulación la posibilidad de abandono de los estudios por parte del alumno. De hecho, hay mayor homogeneidad, medida en 
términos de varianza, en las cohortes, especialmente en la cohorte de 1990, que en algunas carreras parece señalar tal circunstancia. Esto no es obstáculo para que algunas carreras muestren un grado de homogeneidad importante a lo largo de las tres cohortes. Tales son los casos de Empresariales, Ingeniería, Geografía e Historia y Derecho. Sin embargo, la heterogeneidad de resultados es la característica en Físicas, Educación, Psicología, Económicas o Químicas.

Una primera aproximación podría desembocar en la conclusión de que la proporción de abandonos aumenta con el número de alumnos matriculados. Es decir, a mayor número de alumnos, no sólo aumenta proporcionalmente el número de personas que abandonan sus estudios sino que también aumenta tal proporción. Desde la observación global de las tres cohortes no parece existir una notable correlación entre el número de matriculados y el número de abandonos, cuestión que llevaría a buscar la explicación en la evolución y características internas de cada carrera. Es más, si la observación permanece en las dos primeras cohortes, se puede comprobar cómo titulaciones tan numerosas en alumnos como Derecho y Psicología son las que se encuentran entre las de porcentajes relativos de abandono más bajo. Algo que mantiene Derecho en la última cohorte observada. Sin embargo, una titulación con relativos pocos alumnos, como Ingeniería, muestra una historia de altos porcentajes de abandonos, siempre hablando desde la comparación entre unas carreras y otras. Con ello, el estudio parece acercarse a la conclusión de que no es la masificación industrial y, por lo tanto, una de las características esenciales atribuidas a la enseñanza a distancia la causa diferencias con respecto al abandono sino la particular exigencia y tradición en la exigencia al alumnado en las carreras que se ofrecen en los estudios universitarios a distancia las que crean la diferencia entre las mismas.

Puede sorprender el notable aumento del abandono en la última cohorte estudiada. No obstante, tal vez sea demasiado pronto para evaluar el abandono en esta cohorte, ya que la suposición de que una parte importante de quienes la han dejado pueda volver tiene su base.

A la hora de afrontar el abandono y, sobre todo, el porcentaje de abandono emerge la duda sobre la base que ha de tomarse: ¿el total de alumnos matriculados que empiezan la carrera? ¿sólo aquéllos que realizan alguna actividad, como presentarse a uno de los exámenes del curso académico? Al respecto hay que señalar que, por ejemplo, alrededor del $40 \%$ de los matriculados en alguna de las asi gnaturas de Primer Curso de la carrera de Derecho, la más numerosa en la UNED, no se presentan en ninguna de sus convocatorias. Una parte importante de esta proporción no vuelve a matricularse. Por lo tanto, una vez que se haya hecho el estudio ad hoc sobre los que no muestran actividad universitaria al guna, reflejada en la presentación a alguna de las pruebas de evaluación, el porcentaje de abandonos podría hacerse en función del número de alumnos activos, que han mostrado alguna actividad, y no a partir del de matriculados, lo que reduciría de manera importante el porcentaje de abandonos. 


\section{LAS DIFERENGIAS SEGÚN EL GÉNERO}

Centrados ya en los que han Ilegado, interesa establecer distintos análisis en función de variables como el género y la edad, que son las dos variables sociodemográficas básicas que se recogen con la matrícula. Para cada unidad cohorte-titulación se han obteni do las proporciones de varones y mujeres que han obtenido la titulación con respecto al total de los que respectivamente se matricularon. Así, introduciendo la tabla XVI, en la cohorte del año 1980 de la carrera de Derecho (DERECHO 80), finalizó la carrera el $27 \%$ de las mujeres que se matricularon por primera vez en aquel año y el $32 \%$ de los varones.

Tabla XVI: Porcentajes de varones y mujeres que acaban la carrera, por titulación y cohorte

\begin{tabular}{|c|c|c|c|}
\hline & $\%$ acaban mujeres & $\%$ acaban varones & $\begin{array}{c}\text { Diferencia } \\
\text { \%Varones y \%Mujeres }\end{array}$ \\
\hline DERECHO 80 & 27 & 32 & 5 \\
\hline DERECHO 85 & 23 & 26 & 3 \\
\hline DERECHO 90 & 12 & 14 & 2 \\
\hline ECONOMICAS 80 & 44 & 35 & -9 \\
\hline ECONOMICAS 85 & 23 & 26 & 3 \\
\hline ECONOMICAS 90 & 4 & 5 & 1 \\
\hline EDUCACION 80 & 34 & 27 & -7 \\
\hline EDUCACION 85 & 50 & 39 & -11 \\
\hline EDUCACION 90 & 13 & 18 & 5 \\
\hline EMPRESARIAL 85 & 9 & 9 & 0 \\
\hline EMPRESARIAL 80 & 2 & 4 & 2 \\
\hline EMPRESARIAL 90 & 5 & 4 & -1 \\
\hline FILOLOGIA 80 & 19 & 33 & 14 \\
\hline FILOLOGIA 85 & 25 & 15 & -10 \\
\hline FILOLOGIA 90 & 6 & 5 & -1 \\
\hline FILOSOFIA 90 & 4 & 7 & 3 \\
\hline FISICAS 80 & 0 & 20 & 20 \\
\hline FISICAS 85 & 38 & 30 & -8 \\
\hline FISICAS 90 & 8 & 6 & -2 \\
\hline GEOG-HIST 80 & 27 & 18 & -9 \\
\hline GEOG-HIST 85 & 24 & 25 & 1 \\
\hline GEOG-HIST 90 & 6 & 7 & 1 \\
\hline INGENIEROS 80 & - & 18 & - \\
\hline INGENIEROS 85 & 0 & 15 & 15 \\
\hline
\end{tabular}


Javier Callejo

\begin{tabular}{lrrr}
\hline INGENIEROS 90 & 5 & 3 & -2 \\
MATEMATICAS 80 & 25 & 4 & -21 \\
\hline MATEMATICAS 85 & 16 & 8 & -8 \\
MATEMATICAS 90 & 2 & 3 & 1 \\
\hline POLITICAS 90 & 5 & 6 & 1 \\
PSICOLOGIA 80 & 28 & 33 & 5 \\
PSICOLOGIA 85 & 29 & 30 & 1 \\
PSICOLOGIA 90 & 9 & 10 & 1 \\
QUIMICAS 80 & 57 & 37 & -20 \\
QUIMICAS 85 & 46 & 41 & -5 \\
QUIMICAS 90 & 10 & 10 & 0 \\
SOCIOLOGIA 90 & 6 & 9 & 3
\end{tabular}

Como puede observarse, las diferencias entre las proporciones de varones y mujeres que se titulan en cada carrera varía notablemente entre unas carreras y otras. Diferencias que, por otro lado, habría que ponderar en función de la proporción del total de titulados por alumnos matriculados en la cohorte. Es decir, no es lo mismo una diferencia de dos puntos entre las proporciones de varones y mujeres cuando la proporción global es de, por ejemplo, 50\%, que cuando es de un $5 \%$.

Hay al gunos datos de la tabla XVI que han de ser comentados, como el hecho de que ninguna de las pocas mujeres que se matricularon en las cohortes de Físicas de 1980 o de Ingenieros de 1985 hayan podido terminar la carrera iniciada. Por otro lado, la cohorte de Ingenieros de 1980 aparece vacía en la casilla de las mujeres, ya que no había ninguna entre sus componentes, ni en el principio, ni, por supuesto, en el final de la misma.

En función de la escasa diferencia entre las proporciones de titulados, entre los matriculados, de cada uno de los géneros, puede hablarse de titulaciones bastante igualitarias, en la medida que las diferencias son escasas. Tal circunstancia se da en las carreras de Empresariales, Geografía e Historia y Psicología, con la destacada particularidad de que la escasez de la diferencia en la primera titulación viene dada por la pequeña proporción global de titulados; mientras que en las otras dos titulaciones las proporciones de titulados globales superan el $25 \%$.

A lo largo de las tres cohortes, la mayor parte de las titulaciones observadas presentan saldos unas veces favorables a las mujeres, otras a los varones. No obstante, puede establecerse una mínima distinción en algunas de ellas, señalando a Químicas como la titulación más favorable a las mujeres y a Derecho como la más favorable a los varones, aun cuando con la salvedad de que las diferencias entre las proporciones de géneros son menores en el segundo caso. 
Volviendo a la unidad titulación-cohorte, que presenta la tabla XVII, puede observarse cómo las diferencias son más extremas en las cohortes de 1980 y 1985, suavizándose para el caso de la cohorte de 1990. Es como si, en este aspecto, se hubieran dados pasos hacia cierta homogeneización.

Las mayores diferencias favorables a la mujer se encuentran en las Matemáticas y Químicas de la cohorte de 1980, superando los veinte puntos porcentuales. Es decir, disciplinas que no se encuentran entre las que habitualmente se tienen por «carreras feminizadas», pues la presencia de la mujer no es dominante. Las diferencias favorables a los varones son mayores en Físicas de 1980 e Ingenieros de 1985. También sobresale el carácter cambiante, en este aspecto, de carreras como Educación y Filología, con unas cohortes bastante favorables a las mujeres (año 1985) y otras favorables a los varones (1990 y 1980 respectivamente).

Tabla XVII: Orden de Titulación-Cohorte a partir de la diferencia entre porcentajes de titulados varones-mujeres

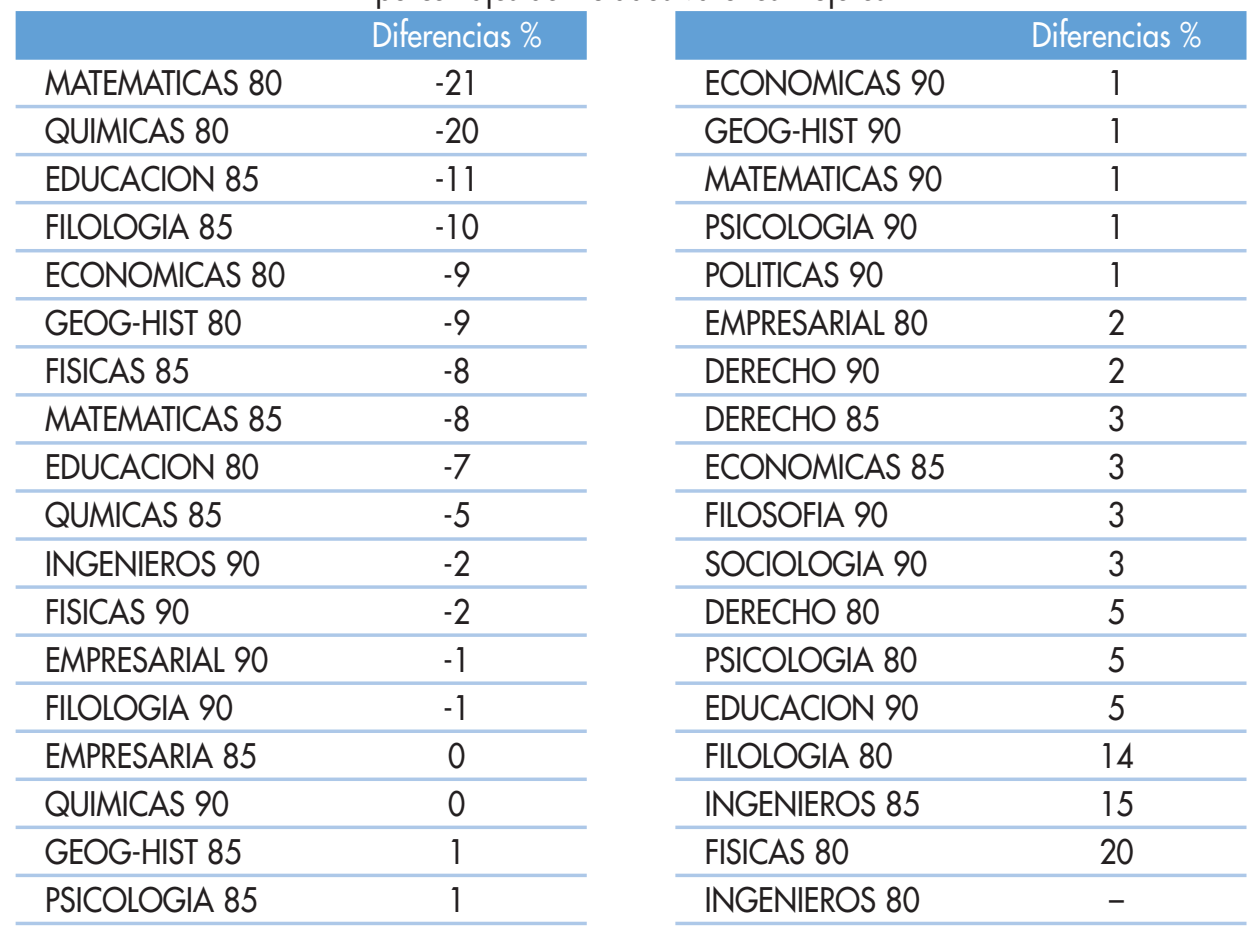


En el siguiente gráfico de dispersión, se recogen en el eje horizontal los porcentajes de varones que han logrado la titulación, entre el total de los mismos que se matricularon; mientras que en el vertical se recogen los porcentajes para el caso de las mujeres. A modo indicativo, la línea diagonal divide las distintas titulaciones-cohorte entre las que han sido favorables a las mujeres, por encima de la línea, y las que han sido favorables a los varones, por debajo de la línea.

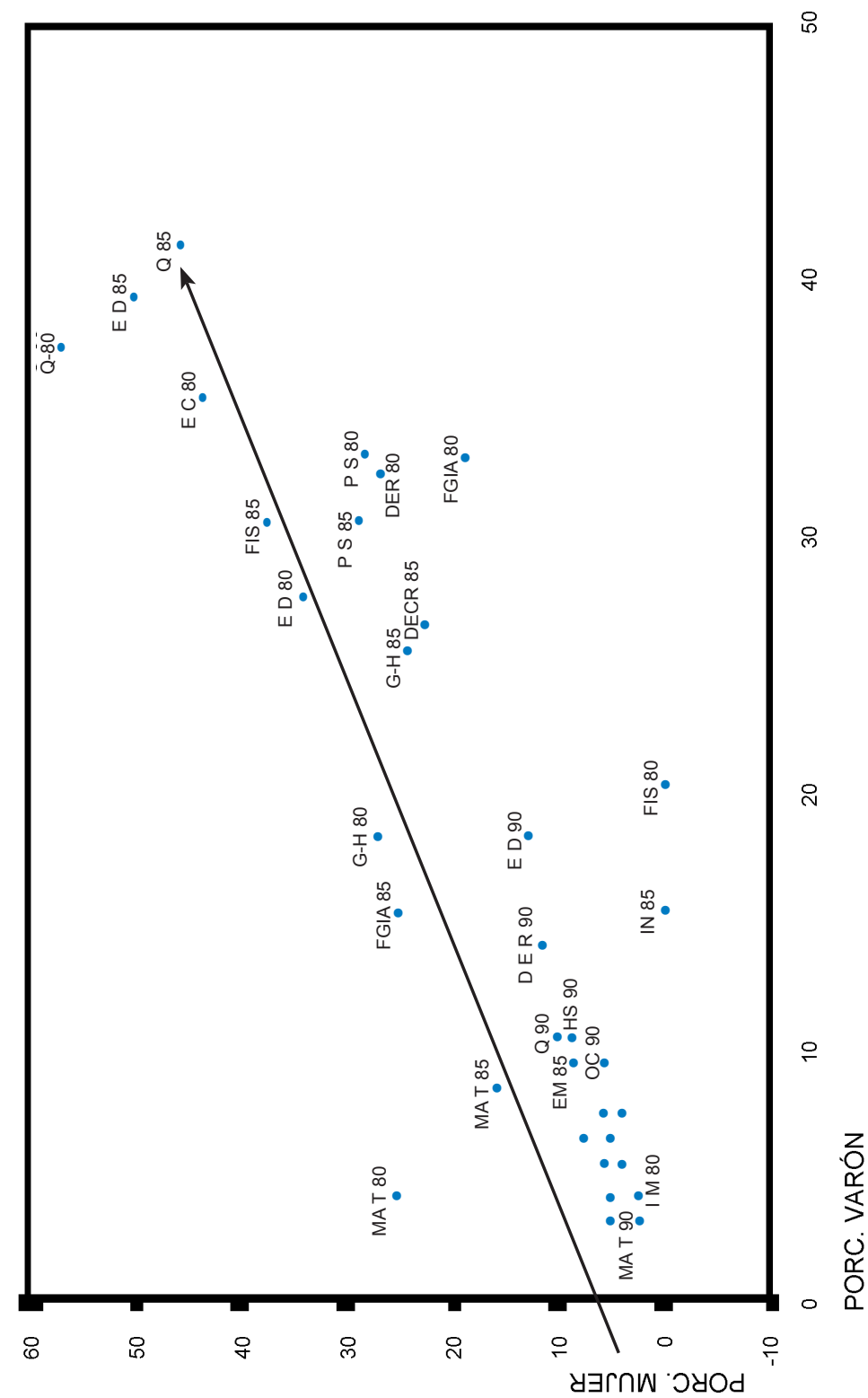


Estudio de Cohorte de Estudiantes de la UNED: una Aproximación al Análisis del Abandono

\section{GOHORTES SEGÚN LA EDAD}

A la hora de comparar las proporciones de titulados según la edad en el momento de la primera matriculación, son los más jóvenes, los que tienen me nos de 25 años los que parecen obtener mejores resultados, aun cuando pueden considerarse importantes las diferencias según las titulaciones. La observación de la tabla XVIII pone de manifiesto, al menos, las mayores dificultades de los alumnos que tienen una edad relativamente avanzada cuando inician la carrera, en especial a partir de los 55 años. Aun cuando suele ser un contingente relativamente pequeño en cada una de las carreras, también son muy pocos o ninguno los que consiguen titularse.

De manera aproximativa y siempre en términos relativos para cada una de las carreras, puede hablarse de titulaciones especialmente favorables a los más jóvenes, como son Filología, Empresariales, Ingenieros, Sociología y Políticas y la cohorte de 1985 de Matemáticas. Se encuentran entre las de que parecen más favorables a los alumnos más adultos las carreras de Derecho, Geografía e Historia y las cohortes de 1985 de Físicas y Psicología, posiblemente debido a que se trata de alumnos que provienen de otras universidades. Favorables al intervalo de edad que puede considerarse medio, entre 25 y 40 años, se encuentras las carreras de Químicas, Educación y Psicología.

De manera especial, además de las ya mencionadas, destacan las altas proporciones experimentadas por los alumnos de la cohorte de 1980 de menos de 25 años de Filología, entre 41 y 55 años de Económicas, de más de 55 años de Geografía e Historia y de menos de 20 años de Ingenieros, pues en todos los casos obtuvieron la titulación la mitad o más de sus componentes. Misma circunstancia que se observa en los alumnos más jóvenes de Matemáticas de la cohorte de 1985, además de las ya referidas de adultos de Físicas y semi-adultos (26-40 años) de Químicas y Educación. Ha de subrayarse que la cohorte de 1990, en la medida que los porcentajes globales de alumnos que consiguen la titulación disminuyen considerablemente con respecto a las cohortes anteriores, no muestra grupos de edad-titulación-cohorte en los que la proporción de titulados alcance el umbral del $50 \%$.

En cualquier caso, a la luz de la tabla XVIII, la varianza en cada uno de los grupos de edad es tan alta que impide llegar a la conclusión de que es ésta variable la que marca las diferencias. Es más, es la titulación la que parece explicar en mayor medida la variación, encontrándose titulaciones bastante homogéneas en su distribución, con relativa independencia de la cohorte y el grupo de edad, como es el caso de Empresariales, con una constante proporción baja de titulados entre sus cohortes de matriculados, además de las titulaciones de Filosofía, Ciencias Políticas y Sociología, cuya homogeneidad viene dada por la observación de una única cohorte. Sin embargo, hay otras titulaciones que presentan una notable heterogeneidad en sus datos, como es el caso de Químicas y Filología. 
Tabla XVIII: Porcentajes de titulados por matriculados, según grupos de edad, titulación y cohorte

\begin{tabular}{|c|c|c|c|c|c|c|}
\hline & $\%+55$ & $\% 41-55$ & $\% 31-40$ & $\% 26-30$ & $\% 21-25$ & $\%$ menos 20 \\
\hline DERECHO 80 & 33 & 36 & 35 & 33 & 20 & 32 \\
\hline DERECHO 85 & 38 & 34 & 26 & 26 & 20 & 26 \\
\hline DERECHO 90 & 0 & 11 & 13 & 11 & 11 & 19 \\
\hline ECONOMICAS 80 & - & 55 & 40 & 23 & 41 & 36 \\
\hline ECONOMICAS 85 & - & 12 & 30 & 22 & 22 & 42 \\
\hline ECONOMICAS 90 & 0 & 0 & 4 & 4 & 5 & 6 \\
\hline EDUCACION 80 & - & 0 & 31 & 33 & 33 & 0 \\
\hline EDUCACION 85 & - & 36 & 46 & 52 & 44 & 44 \\
\hline EDUCACION 90 & 0 & 16 & 14 & 15 & 12 & 17 \\
\hline EMPRESARIA 85 & 0 & 3 & 10 & 7 & 10 & 17 \\
\hline EMPRESARIAL 80 & - & 0 & 0 & 3 & 6 & 14 \\
\hline EMPRESARIAL 90 & 0 & 5 & 2 & 3 & 7 & 8 \\
\hline FILOLOGIA 80 & - & 0 & 13 & 17 & 75 & 50 \\
\hline FILOLOGIA 85 & - & 17 & 33 & 12 & 19 & 29 \\
\hline FILOLOGIA 90 & 0 & 6 & 4 & 6 & 7 & 22 \\
\hline FILOSOFIA 90 & 0 & 6 & 3 & 8 & 8 & 28 \\
\hline FISICAS 80 & 0 & 0 & 15 & 21 & 30 & 0 \\
\hline FISICAS 85 & - & 67 & 28 & 35 & 28 & 28 \\
\hline FISICAS 90 & 0 & 0 & 3 & 7 & 7 & 4 \\
\hline GEOG-HIST 80 & 50 & 13 & 31 & 20 & 14 & 28 \\
\hline GEOG-HIST 85 & 14 & 30 & 28 & 25 & 18 & 23 \\
\hline GEOG-HIST 90 & 0 & 7 & 6 & 6 & 6 & 17 \\
\hline INGENIEROS 80 & - & 0 & 0 & 33 & 0 & 50 \\
\hline INGENIEROS 85 & - & 0 & 0 & 0 & 10 & 30 \\
\hline INGENIEROS 90 & - & 0 & 0 & 1 & 4 & 5 \\
\hline MATEMATICAS 80 & - & - & 29 & 0 & 0 & 25 \\
\hline MATEMATICAS 85 & - & 20 & 0 & 10 & 12 & 50 \\
\hline MATEMATICAS 90 & 0 & 0 & 3 & 1 & 5 & 2 \\
\hline POLITICAS 90 & 0 & 8 & 4 & 7 & 5 & 10 \\
\hline PSICOLOGIA 80 & - & 20 & 33 & 37 & 25 & 22 \\
\hline PSICOLOGIA 85 & - & 35 & 29 & 31 & 26 & 31 \\
\hline PSICOLOGIA 90 & 0 & 7 & 10 & 7 & 10 & 21 \\
\hline QUIMICAS 80 & - & - & 50 & 57 & 29 & 25 \\
\hline QUIMICAS 90 & - & 10 & 12 & 11 & 11 & 4 \\
\hline QUIMICAS 85 & - & 0 & 45 & 73 & 31 & 33 \\
\hline SOCIOLOGIA 90 & 0 & 8 & 8 & 6 & 7 & 16 \\
\hline
\end{tabular}


La juventud, en general, aparece como una categoría favorecida, con mayores probabilidades de conseguir la titulación si se tiene menos de 25 años al comenzar la carrera. Sin embargo, a la hora de establecer la correspondiente correlación entre proporción de presencia de menores de 25 años en la titulación de cada cohorte y porcentaje de titulados, sobre total de matriculados, en la misma apenas tiene intensidad. Es positiva; pero escasa. No obstante, la mayor presencia de jóvenes, menores de 25 años en la titulación, sí parece facilitar que sean más los que proporcionalmente logren superar el primer ciclo de las carreras al completo. Así, el coeficiente de correlación entre la proporción de jóvenes que, en una cohorte y una titulación, inician la carrera y la de alumnos que superan el primer ciclo es de 0,4 (estadísticamente significativo a un nivel del 0,05$)$, cuando se excluye al guna de las titulaciones que muestran datos con escasa proporción de alumnos que superan este primer ciclo, como ocurre con la cohorte de Ingenieros de 1990 (sólo alcanzan el primer ciclo el 7\%). Relación que no sucede cuando se observa la proporción de licenciados total en cada cohorte-titulación, de los que acaban en cinco años o los que lo hacen en menos de diez años. A tenor de estos resultados, parece derivarse que los jóvenes tienen mayores probabilidades de titularse, al go que puede achacarse a una dedicación exclusiva al estudio de la que seguramente no disponen otros grupos de edad; pero que tal probabilidad viene, sobre todo, del impulso inicial que les lleva a acabar más tempranamente el primer ciclo. Después, puede hablarse de una especie de parón o ralentización, donde pueden intervenir factores tan dispares como: cansancio, mayores dificultades en los segundos ciclos de las carreras, paso de la dedicación exclusiva a otras obligaciones laborales o familiares, etc.. En este último aspecto, ha de destacarse que una parte importante de estos jóvenes menores de 25 años se matriculan en la UNED por la flexibilidad que esta oferta universitaria les ofrece, ante la posibilidad de encontrar algún tipo de empleo mientras están llevando a cabo sus estudios.

Las posibles consecuencias de las características del alumnado de la carrera, en función de la edad en esta ocasión, sobre los datos aportados por la misma, nos sitúa en la reflexión de la comparación de tales características en las carreras de cada cohorte. En los siguientes cuadros estadísticos y gráficos, se presentan los lugares ocupados por las carreras, en cada uno de los años observados, según las características de edad (proporción de alumnos menores de 25 años) y géne ro (proporción de mujeres) en cada cohorte. EI análisis de los gráficos resulta altamente ilustrativo, pues se observa cómo de una clara escisión entre, por un lado, carreras masculinas, y, por otro, carreras femeninas, las primeras se van acercando a las segundas con el paso de una cohorte a otra. En los gráficos de las dos últimas cohortes, queda patente la oposición representada por Ingenieros, masculina y joven, y Educación, femenina y más adulta. Es decir, la evolución de la UNED parece tender a tal polarización, junto a un núcleo central en el que género y edad están más equilibrados. 
Proporción de menores y mujeres en la cohorte 1980

\begin{tabular}{lcc} 
Titulación & \% menores de 25 & $\%$ mujeres \\
\hline DERECHO 80 & 59,3 & 32,6 \\
\hline ECONOMICAS 80 & 34,9 & 10,5 \\
\hline EDUCACION 80 & 51,7 & 63,3 \\
\hline EMPRESARIAL 80 & 33,7 & 12,5 \\
\hline FILOLOGIA 80 & 27,8 & 58,3 \\
\hline FISICAS 80 & 27,1 & 8,3 \\
\hline GEOG-HIST 80 & 32,3 & 51,7 \\
\hline INGENIEROS 80 & 47,1 & 0 \\
\hline MATEMATICAS 80 & 58,9 & 23,5 \\
\hline PSICOLOGIA 80 & 43 & 58,5 \\
\hline QUIMICAS 80 & 42,3 & 26,9 \\
\hline
\end{tabular}

Proporción de menores y mujeres en la cohorte 1985

\begin{tabular}{lcc} 
Títulación & $\%$ menores de 25 & $\%$ mujeres \\
DERECHO 85 & 65,9 & 41,9 \\
\hline ECONOMICAS 85 & 46,6 & 27,1 \\
\hline EDUCACION 85 & 19,7 & 67,6 \\
\hline EMPRESARIA 85 & 43,5 & 22,8 \\
\hline FILOLOGIA 85 & 67,3 & 37,6 \\
\hline FISICAS 85 & 41,1 & 13,7 \\
\hline GEOG-HIST 85 & 36 & 54,7 \\
\hline INGENIEROS 85 & 73,6 & 6,9 \\
\hline MATEMATICAS 85 & 42,7 & 27,9 \\
\hline PSICOLOGIA 85 & 49,2 & 62,2 \\
\hline QUMICAS 85 & 44,4 & 36,1 \\
\hline
\end{tabular}


Estudio de Cohorte de Estudiantes de la UNED: una Aproximación al Análisis del Abandono

Proporción de menores y mujeres en la cohorte 1990

\begin{tabular}{lcc} 
Titulación & \% menores de 25 & $\%$ mujeres \\
DERECHO 90 & 38,6 & 42,9 \\
\hline ECONOMICAS 90 & 41,4 & 28,3 \\
\hline EDUCACION 90 & 14,7 & 67,7 \\
\hline EMPRESARIAL 90 & 47,2 & 34,6 \\
\hline FILOLOGIA 90 & 23,3 & 67,6 \\
\hline FILOSOFIA 90 & 27,4 & 32,6 \\
\hline FISICAS 90 & 43,4 & 14,3 \\
\hline GEOG-HIST 90 & 21,3 & 57,0 \\
\hline INGENIEROS 90 & 63,7 & 12,6 \\
\hline MATEMATICAS 90 & 37,6 & 32,4 \\
\hline POLITICAS 90 & 31,9 & 44,5 \\
\hline PSICOLOGIA 90 & 29,2 & 60,6 \\
\hline QUIMICAS 90 & 39,8 & 30,4 \\
\hline SOCIOLOGIA 90 & 21,1 & 47,2 \\
\hline
\end{tabular}

CARACTERÍSTICAS COHORTE 1980 GÉNERO Y EDAD

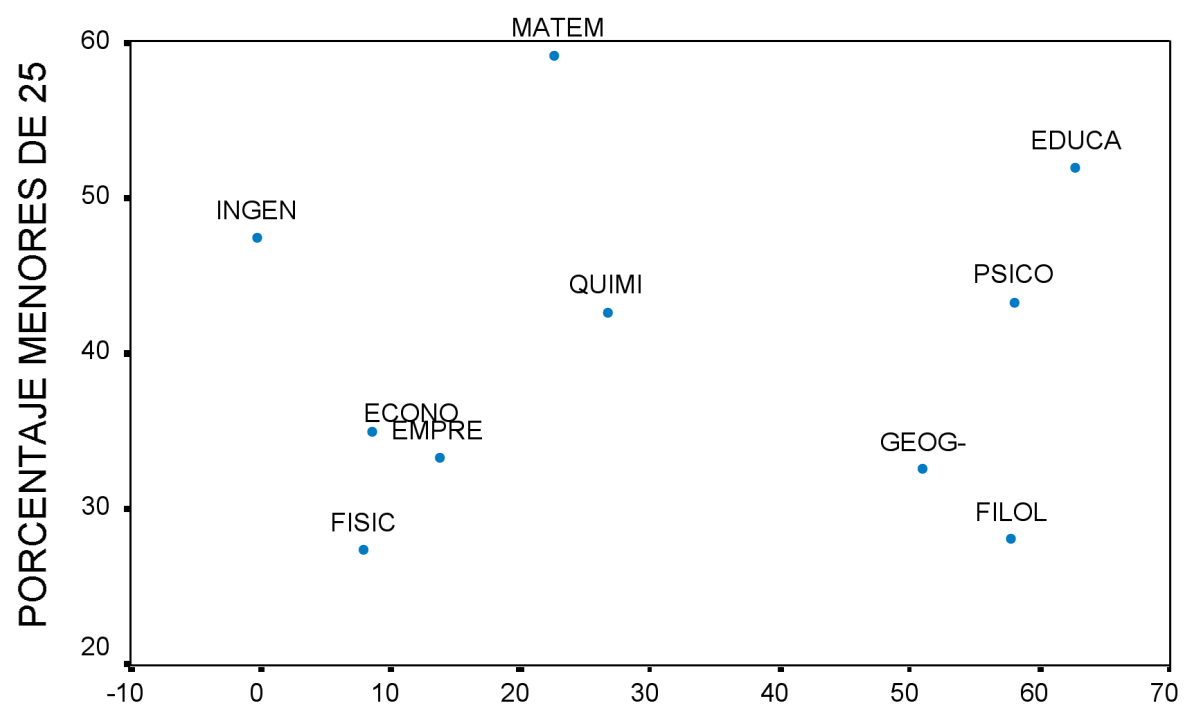

PORCENTAJE MUJERES 
CARACTERÍSTICAS COHORTE 1985 GÉNERO Y EDAD

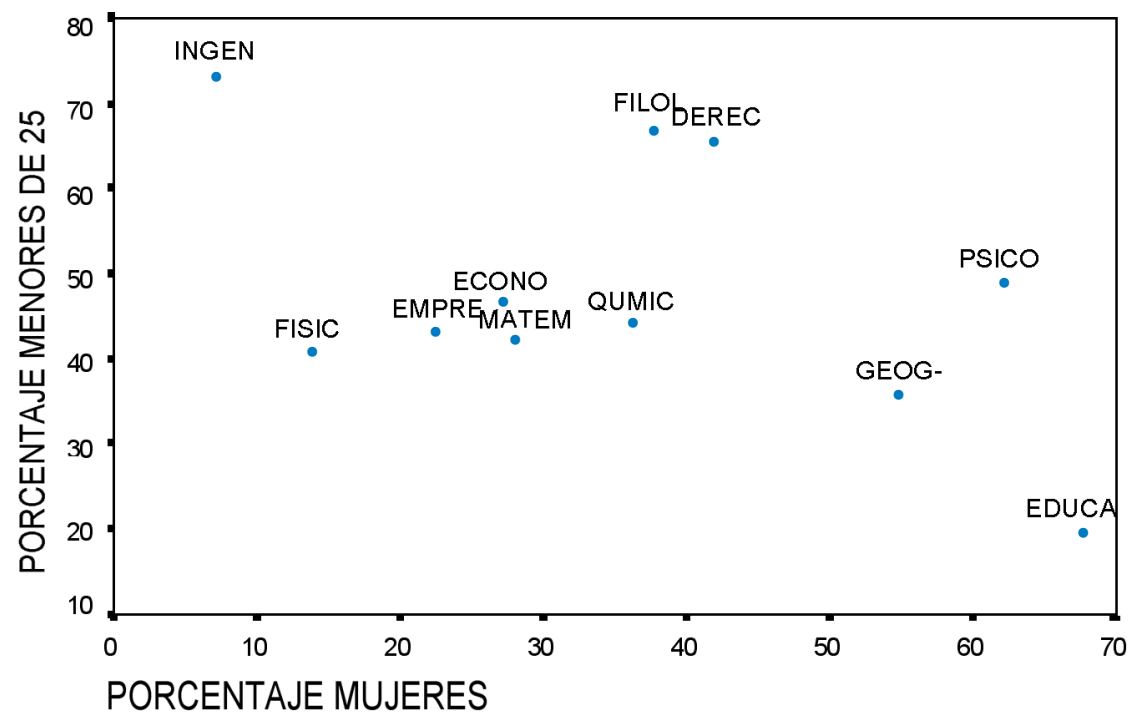

\section{CARACTERÍSTICAS COHORTE 1990 GÉNERO Y EDAD}

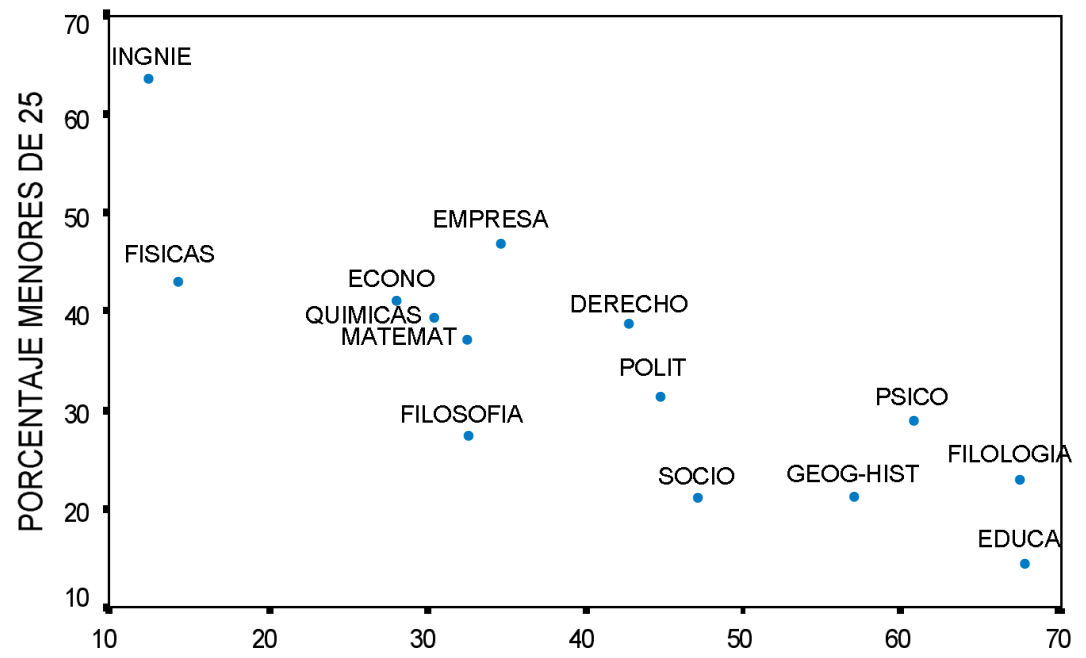

PORCENTAJE MUJERES 
Estudio de Cohorte de Estudiantes de la UNED: una Aproximación al Análisis del Abandono

\section{GONGLUSIONES PROVISIONALES}

El estudio ha puesto de manifiesto la necesidad de reflexionar sobre el significado del término abandono en el ámbito de la enseñanza a distancia, más allá de la tipología, pues entre el abandono sin comenzar y el abandono real, tomando la propuesta de García Aretio (2001:161), pueden darse situaciones intermedias que tienden a ubicarse del lado del segundo. Algo que desfavorece notablemente a la enseñanza a distancia, en especial cuando la comparación se establece con la presencial. Desde tal perspectiva, el estudio no ha incidido en las causas que conducen al abandono, como previamente han hecho las interesantes investigaciones de Aretio (1987) y Granados (1992), que también toman a la UNED como referencia. De inscribirse en alguna reflexión, lo hace en la iniciada hace tiempo en la División de Investigación del anterior Instituto de Ciencias de la Educación, ahora Instituto Universitario de Educación a Distancia (Farjas y otros 1996), en cuanto hace hincapié en: la ausencia de homogeneidad en un comportamiento como el abandono, existiendo distintos tipos de abandono; los distintos registros presentados por las carreras al respecto; y el apunte de que, tal vez siendo algo más elevadas que en el caso de la universidad presencial, las tasas de abandono en esta universidad a distancia no son tan altas como podría parecer en un principio, especialmente en algunas de sus titulaciones, con el añadido de que se ha de considerar el tiempo, en cuanto elemento gestionado por el estudiante, de manera distinta.

Desde un marco temporal relativamente amplio, que llega hasta los diecinue ve años, y tomando como referencia tres cohortes de estudiantes (matriculados inicialmente en el primer ciclo de las distintas titulaciones en 1980, 1985 y 1990), se ha constatado la notable diferencia entre las titulaciones en cuanto a registros de alumnos que abandonan y de alumnos que continúan. Precisamente porque el estudio se ha realizado desde la perspectiva del largo plazo, se ha podido observar cómo un relevante núcleo de alumnos continúan sus estudios durante casi veinte años, aun cuando hayan realizado diversas interrupciones. Un tipo de alumno que supera el 10 por ciento en algunas de las carreras. Por lo tanto, además de la distinta gestión del tiempo de estudio que parece presentar un sector del alumnado de la enseñanza superior a distancia, se subraya la necesidad de que los estudios sobre evolución de los alumnos han de contemplar períodos temporales suficientemente amplios.

Si el importante número de alumnos, de carácter masivo en esta universidad, facilita la adopción de un modelo industrial (Peters 1983), éste no ha aparecido vinculado con la mayor o menor tendencia al éxito (titulación) o fracaso (abandono) de tales alumnos. Es más, han sido las propias titulaciones las que han aparecido como notable fuente explicativa de las diferencias en la evolución de los estudiantes. Titulaciones en lo que tienen de particulares características de sus planes de estudio, tradición en las formas de evaluación de sus futuros profesionales y aplicación concreta de la enseñanza a distancia. De esta manera, 
se indica la dirección que han de tomar los futuros estudios sobre el abandono, dando un especial relieve a las particularidades de cada oferta de enseñanza a distancia, en lugar de establecerse como algo general de ésta.

En cuanto a las características de los alumnos, el género no ha aparecido como especial condición para asegurar más el éxito o el fracaso. No obstante, se señala que las mujeres aparece con mayores probabilidades de conseguir la titulación en aquéllas carreras en las que, precisamente, son una pequeña minoría. La edad también aparece con un ligero peso causal, favoreciendo el éxito de los más jóvenes, pero nuevamente en menor grado que la titulación. Por último, ha de tenerse en cuenta que la actuación de tales características es netamente débil si, como ocurre en el evolución de la UNED, junto a un núcleo central formado por titulaciones relativamente equilibradas en cuanto a la presencia de mujeres y jóvenes, se acentúa la polarización en titulaciones jóvenes con muy pocas mujeres y, por el otro lado, titulaciones con pocos estudiantes jóvenes, con importante presencia de mujeres.

\section{REFERENGIAS BIBLIOGRÁFICAS}

Farjas, A., C. Madrigal y E. Nogales (1996): «La UNED y sus alumnos», en García Aretio, La educación a distancia y la UNED. Madrid: IUED-UNED.

García Aretio, L. (1987): Rendimiento académico y abandono en la educación superior a distancia. Madrid: ICE-UNED.

García Aretio, L. (2001): La educación a distancia. Dela teoría a la práctica. Barcelona: Ariel.

Granados G. Tenorio, P. (1992): Abandono de estudios en las Facultades de Letras de la UNED. Madrid: ICE-UNED.

J USTICIA JUSTICIA, F. (1990): El rendimiento académico en la universidad de Granada: análisis de una cohorte (1979-80) de las facultades de Letras y Ciencias. Granada: Universidad de Granada.

Peters, O. (1983): «Distance teaching and industrial production: a comparative interpretation», en Sewart, Keegan y Holmberg (eds.), Distance Education. International Perspectives. Londres: Croom Helm. 


\title{
PERFIL ACADÉMICO Y PROFESIONAL DEL AUTOR:
}

Javier Callejo es doctor en Sociología y Licenciado en CC. de la Información (Periodismo). En los últimos años, ha realizado distintas investigaciones en los campos de la sociología de los medios de comunicación de masas y del consumo, de las que ha dado razón en las principales revistas especializadas. Autor del libro La audiencia activa (1995) y co-autor de diversas obras. Actualmente es Profesor Titular de Sociología en la Facultad de CC. Políticas y Sociología de la UNED y Director Adjunto del Instituto Universitario de Educación a Distancia (UNED)

\author{
Instituto Universitario de Educación a Distancia \\ UNED \\ Ciudad Universitaria \\ 28040 Madrid (España) \\ Telf. 913986685 \\ Fax. 913986693 \\ Dirección electrónica: mcallejo@poli.uned.es
}

